Colour Tests for the Examination of the Colour Sense. Twentieth Revised Edition of Stilling's Plates. Edited by Geheimrat Professor Dr. E. Hertel, Leipzig. Thirty-five coloured charts and 16 pages of directions for use. Leipzig: Georg Thieme. Price, R.M. 14. (English edition, 24/6).

In the 20th revised edition of Stilling's plates the variety of the tests has been increased by the introduction of new plates with numbers and letters in confusion colours chosen from regions of the spectrum not hitherto considered. The editor believes that the diagnosis of colour defect is facilitated by these additions, particularly in group testing.

Some of the tests are constructed with reference to the higher sensitivity of the colour defective to differences of brightness. Plates have also been added which reveal that heightening of the contrast effect (simultaneous contrast) which so frequently accompanies colour defect. Plates 3 to 31 are for the detection of red-green sensitivity, and 32 to 35 for the rarer disturbances of yellow-blue sensitivity.

The English edition has been translated by Prof. James Drever, of Edinburgh University.

\title{
CORRESPONDENCE
}

\section{DIET IN RELATION TO HEALTH}

To the Editors of THE BRITISH JOURNAL OF OPHTHALMOLOGY

DEAR SIRS,-The essay on Diet in Relation to Health which appeared in the November, 1939 issue, is full of interest though not quite conclusive. During 1917.18 I was a medical officer employed in the man power problem in Egypt and Palestine. Details are set out in a work of mine entitled "A Vision of the Possible."

It came to notice that a number of soldiers complained of night blindness and tripping over tent ropes, etc. After a time I reached the conclusion that some of the complaints must be genuine. None of them had any appearance of retinitis pigmentosa. After entry into Palestine one heard little about it. Though the diet of the soldier was good on the whole there was not the abundance of fruit which was available in Palestine. I suspected without proof that some deficiency in diet may have accounted for these cases. But Jaffa oranges would not supply vitamin A.

$$
\begin{aligned}
& \text { I am, etc., } \\
& \text { Yours very truly, } \\
& \text { JAMES W. BARRETT. }
\end{aligned}
$$$$
\text { Melbourne. }
$$ 